\title{
The effect of HES130/0.4 sodium chloride solution on kidney function following early fluid resuscitation in shock patients
}

\author{
Haiyan Jiang, ${ }^{1,2 \#}$, Yuting Ren ${ }^{1,2 \#}$, Guangdong $\mathrm{Qi}^{3 \#}$, Yue Wang ${ }^{1}$, Cheng $\mathrm{Xu}^{1}$, Guomin Mao ${ }^{1}$, Guiwen Liang ${ }^{1}$, \\ Dajun Yan ${ }^{1}$, Yan Yan ${ }^{1}$, Yansong Dong ${ }^{1}$, Zhongwei Huang ${ }^{1,2}$, Lei Qi ${ }^{1,2,4}$ \\ ${ }^{1}$ Department of Emergency Medicine, Affiliated Hospital of Nantong University, Nantong, China; ${ }^{2}$ Medical College, Nantong University, Nantong, \\ China; ${ }^{3}$ Department of Endocrinology, Binhai County People's Hospital affiliated to Kangda College of Nanjing Medical University, Yancheng, \\ China; ${ }^{4}$ Rugao Branch (Rugao Bo'ai Hospital), Affiliated Hospital of Nantong University, Nantong, China \\ Contributions: (I) Conception and design: H Jiang, Z Huang; (II) Administrative support: G Liang, C Xu; (III) Provision of study materials or patients: \\ L Qi, Y Dong; (IV) Collection and assembly of data: Y Ren, G Qi; (V) Data analysis and interpretation: G Mao, G Liang; (VI) Manuscript writing: \\ All authors; (VII) Final approval of manuscript: All authors. \\ \#These authors contributed equally to this work. \\ Correspondence to: Lei Qi; Zhongwei Huang; Yansong Dong. Department of Emergency Medicine, Affiliated Hospital of Nantong University, 20 \\ West Temple Road, Nantong 226001, China. Email: qilei723@ntu.edu.cn; tdfyhuangzw@163.com; bigbear901114@163.com.
}

Background: Doctors often use a small dose of hydroxyethyl starch (HES) 130/0.4 sodium chloride solution in the emergency room; however, its effect on kidney function remains controversial. This study aimed to evaluate the effect of a small dose of HES130/0.4 sodium chloride solution on kidney function in shock patients during early fluid resuscitation.

Methods: This cohort study retrospectively analyzed the data of 129 shock patients requiring fluid resuscitation who had been admitted to the Emergency Department of the Affiliated Hospital of Nantong University from January 2019 to December 2020. Patients were divided into the observation group ( $\mathrm{n}=40)$ and control group ( $n=89)$ according to the type of fluid resuscitation. In relation to the fluid resuscitation treatment, the observation group was treated with crystalloid solution, while the control group was treated with crystalloid and HES130/0.4 sodium chloride solution. To further explore the effect of a small dose of HES130/0.4 sodium chloride solution, the patients were further divided into the following 4 groups based on the specific fluid administered: (I) the HES(+), lactated Ringer's (LR)(+) group ( $\mathrm{n}=85$ ); (II) the HES(+), LR(-) group ( $n=4)$; (III) the HES(-), LR(+) group (n=31); and (IV) the HES(-), LR(-) group (n=9). The outcomes were in-hospital mortality and changes in creatinine (CR) level after fluid resuscitation.

Results: There were no significant differences in the in-hospital mortality rates between the observation and control groups $(\mathrm{P}=0.343)$. The CR levels of patients in the control and HES(+), LR(+) groups were reduced after fluid resuscitation $(\mathrm{P}=0.034 ; \mathrm{P}=0.028)$. There was no significant change in patients' $\mathrm{CR}$ levels in the HES(+), LR(-) group after fluid resuscitation $(\mathrm{P}=0.999)$.

Conclusions: Administering a small dose of HES 130/0.4 sodium chloride in patients with shock does not appear to affect kidney function and in-hospital mortality; however, these findings should be considered exploratory, and further studies should be conducted to confirm these results.

Keywords: Shock; fluid resuscitation; kidney function; hydroxyethyl starch 130/0.4 sodium solution

Submitted Sep 24, 2021. Accepted for publication Nov 19, 2021.

doi: $10.21037 /$ tau-21-972

View this article at: https://dx.doi.org/10.21037/tau-21-972 


\section{Introduction}

Shock is a medical emergency characterized by hypotension and the reduction of tissue perfusion (1), which can lead to inadequate oxygen delivery to cells and an inability to meet tissue consumption and support organ function, which in turn can aggravate tissue hypoperfusion and cause organ failure. Mortality from septic shock and hemorrhagic shock remains high (2). Indeed, data shows that mortality from septic shock can be as high as $40 \%$ to $70 \%$ and that of hemorrhagic shock is close to $40 \%(3,4)$. The treatment for septic shock is mainly to control infection, while the hemorrhagic shock is to control bleeding. Additionally, acute renal failure (ARF) is an independent factor of mortality (5) in patients with severe sepsis and septic shock. The timely, rapid and effective recovery of tissue perfusion and the improvement of oxygen supply to body tissues are the most effective methods for treating these patients (6). The early resuscitation of septic shock patients can reduce sepsis-related morbidity and mortality (7). Further, fluid therapy can optimize cardiac output, which is supported by the preload, afterload, and contractility of the heart and the heart rate (8). Reports from clinicians suggest that the type of fluid used for resuscitation varies widely $(9,10)$, which suggests that there is a lack of consensus about the most appropriate fluids for resuscitation (11). Generally, resuscitation fluids are categorized as crystalloids or colloids (12).

A recently published clinical trial (13) recommended crystalloid solutions as the most appropriate fluids for initial fluid resuscitation in septic shock patients. Sodium lactate Ringer's (LR) solution is a commonly used equilibrium crystalloid solution. Recently, research on the potential side effects of balanced solutions have shown that they may lead to an increase in lactic acid (14). Colloid fluid has become increasingly popular with clinicians. Colloid solutions are thought to be more efficient than crystalloid solutions in terms of the amount of fluid that remains in the intravascular space (15). Thus, colloids require less fluid than crystalloids to achieve similar hemodynamic goals $(16,17)$. Additionally, colloid solutions can quickly restore blood volume and effectively improve microcirculation and tissue perfusion $(18,19)$. Hydroxyethyl starch (HES) is a synthetic colloid that is commonly used in fluid resuscitation because of its ability to expand blood vessels. Besides, it takes a short time to restore effective blood volume expansion $(11,20)$. However, HES may increase the risk of acute kidney injury (AKI), coagulation, and death.
Many clinical studies have shown that patients with severe sepsis who receive fluid resuscitation with HES 130/0.42 have an increased risk of death and are more likely to require renal replacement therapy than those who receive LR acetate (21). Current guidelines do not recommend the use of HES for intravascular volume replacement in patients with sepsis or septic shock (22). Despite this, doctors tend to use HES in clinical practice, especially in the emergency room, as a large amount of crystalloid solution increases tissue edema. Yang et al. paid attention to the effect of HES130/0.4 on intraabdominal hypertension (IAH) in early fluid therapy of severe acute pancreatitis patients (23). He found that early goal-directed fluid therapy with HES130/0.4 shortened the duration of positive fluid balance, reduced APACHE II score, and relieved IAH. Therefore, we may infer using HES 130/0.4 for early fluid resuscitation in shock patients may not increase the risk of mortality. Research needs to be conducted to determine whether HES 130/0.42 sodium chloride aggravates renal injury. Further, current guidelines do not specify the appropriate dose of HES, and previous research has failed to address this problem. Similarly, little research appears to have been conducted on the effect of a small dose of HES130/0.4 sodium chloride. In order to further explore the effect of HES 130/0.4, we conducted a retrospective cohort study to explore the effect of a small dose of HES 130/0.42 sodium chloride solution on kidney function in shock patients. The clinical data of 129 patients were compared and analyzed, and the research results are reported below. We present the following article in accordance with the STROBE reporting checklist (available at https://dx.doi.org/10.21037/tau-21-972).

\section{Methods}

\section{Patient information}

One hundred twenty-nine shock patients treated between January 2019 and December 2020 were enrolled in the study. To be eligible for enrollment in this study, patients had to meet the following inclusion criteria: (I) be aged over 18 years; and (II) meet the diagnostic criteria of shock. Shock was defined as a combination of (I) hypotension: systolic arterial pressure $<90 \mathrm{mmHg}$, mean arterial pressure $<60 \mathrm{mmHg}$, orthostatic hypotension (i.e., a decrease in systolic arterial pressure of at least $20 \mathrm{mmHg}$ from the supine to the semi-reclining position), or a delta pulse pressure $\geq 13 \%$; (II) low filling pressures and a low cardiac 
index as assessed either invasively or noninvasively; and (III) tissue hypoperfusion or hypoxia, including at least 2 of the following clinical symptoms: a Glasgow Coma Scale score $<12$, mottled skin, urinary output $<25 \mathrm{~mL} / \mathrm{h}$, or a capillary refilling time $\geq 3$ seconds; and arterial lactate levels $>2 \mathrm{mmol} / \mathrm{L}$, blood urea nitrogen $>56 \mathrm{mg} / \mathrm{dL}$, or a fractional excretion of sodium $<1 \%$. Patients were excluded from the study if they met any of the following exclusion criteria: (I) were pregnant; (II) had previously confirmed liver, kidney, or coagulation dysfunction. This study was approved by the Ethics Committee of the Affiliated Hospital of Nantong University (2017-L021), and consent was obtained from the patients and their families. All procedures performed in this study involving human participants were in accordance with the Declaration of Helsinki (as revised in 2013).

\section{Study method}

\section{Study design}

This is a retrospective single, randomized, cohort clinical study. The shock patients were recruited from the Affiliated Hospital of Nantong University (Nantong, China) from January 2019 to December 2020. The type of fluid resuscitation administered and patients' creatinine (CR) levels in the Emergency Department were recorded. Additionally, CR levels after fluid resuscitation and inhospital mortality were also analyzed. Patients were divided into the following 2 groups according to the type of fluid therapy: (I) the observation group, who received crystalloid solution for fluid resuscitation; and (II) the control group, who received crystalloid and HES130/0.4 sodium chloride solution $[<3 \mathrm{~mL} /(\mathrm{kg} \cdot \mathrm{d})]$. To further explore the effect of a small dose of HES130/0.4 sodium chloride solution, the patients were further divided into the following 4 groups based on the specific fluid administered: (I) the HES(+), $\mathrm{LR}(+)$ group; (II) the HES(+), LR(-) group; (III) the HES(-), LR(+) group; and (IV) the HES(-), LR(-) group. Patients in the HES(+), LR(+) group were treated with LR and HES130/0.4 sodium chloride solution. Patients in the HES(+), LR(-) group were treated with HES130/0.4 sodium chloride solution alone. Patients in the HES(-), $\mathrm{LR}(+)$ group were treated with LR alone. Patients in the HES(-), LR(-) group were not treated with either LR or HES130/0.4 sodium chloride solution. The sample size was determined by the number of patients treated at the hospital during the study period.

Patients enrolled in this study were given the following treatments: electrocardiogram monitoring, fluid replacement, and conventional therapy for the primary disease, including active anti-infection, respiratory and nutritional support, the maintenance of water and electrolyte balance, and intracellular homeostasis. The vital signs of the patients were closely observed. The main index of CR before and after resuscitation was included in the analyses. CR was influenced by the use of fluid resuscitation and previous function. In our study, patients with previous renal dysfunction and treated with any nephrotoxic drugs recently were excluded. As this was a retrospective cohort study, the time each person spent in the emergency department differed. To eliminate this bias, patients who stayed less than one day in emergency department were enrolled in this study. Figure 1 shows the design for this research study.

\section{Data collection}

The baseline data of patients (i.e., sex, age, weight, diseases, and vital signs) were collected for this study. Patients' renal function results before and after admission to the emergency room (before resuscitation and after resuscitation) were also analyzed. The serum of creatineine in the observation and control groups were analyzed using an automatic biochemical analyzer in the laboratory department. Doctors in the laboratory department were not aware of the drugs that had been administered to the patients.

\section{Statistical analysis}

The statistical analyses were conducted using GraphPad Prism 8.0 software. The measurement data that conformed to normal distributions are described as mean \pm standard deviation (SD), and non-normal data are described as mean M (Q1, Q3) (Quartiles1, Quartiles 3). The unpaired $t$-test was used for data comparisons between 2 groups. The Mann-Whitney $U$ test was used for comparisons between two groups. One way anova was used for comparisons between four groups. Any missing data were filled using the mean-filling method. SPSS 21 was used to fill the missing data. After filling the missing data, the average did not change, but the SD changed slightly. A comparison of the date before and after filling showed that the statistical results did not change. The $\chi^{2}$ test was used to compare the counting data. A $\mathrm{P}$ value $<0.05$ was considered statistically significant. 


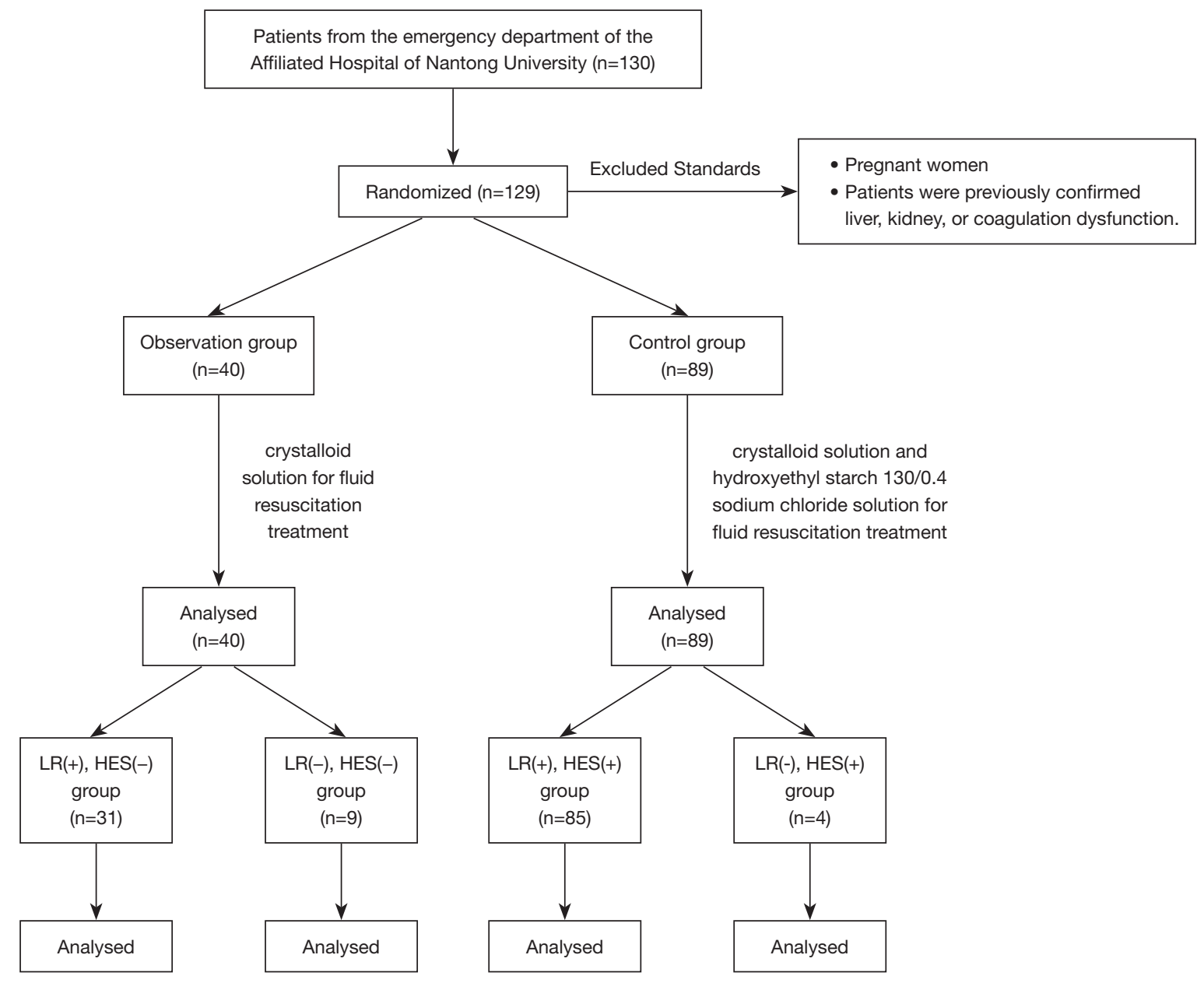

Figure 1 The design of the research study.

\section{Results}

\section{Baseline characteristics}

According to the inclusion and exclusion criteria, 129 patients were enrolled in this study, including 82 males and 47 females, with an average age of $59.33 \pm 15.85$ years. Patients were divided into the control group $(\mathrm{n}=40)$ and observation group ( $n=89$ ) based on the type of fluid resuscitation. The observation group comprised 28 males and 12 females, aged 30 to 82 years old, with an average age of $59.12 \pm 17.91$ years. The control group comprised 54 males and 35 females, aged 22 to 90 years old, with an average age of $59.43 \pm 14.74$ years. Of the 129 patients, 29 had hypertension and 13 had diabetes. On average $806.89 \mathrm{~mL} / \mathrm{d}$ (range, $500-2,000 \mathrm{~mL} / \mathrm{d}$ ) of HES 130/0.4 sodium chloride solution was administered to patients. The basic vital signs (e.g., respiration, heart rate, and mean arterial pressure) were similar between the
2 groups. Only 5 patients had missing the date of CR. The baseline characteristics for the observation and control groups are set out in Table 1.

\section{Main results}

\section{In-hospital mortality}

Of the 129 patients, 13 died in the hospital after resuscitation (11 in the control group and 2 in the observation group). There was no significant difference in the mortality rates between the 2 groups $(\mathrm{P}=0.343)$. Of the 13 patients who died, 10 were in the $\operatorname{HES}(+), \operatorname{LR}(+)$ group, 1 was in the HES(+), LR(-) group, and 2 were in the HES(-), LR(+) group. There was no significant difference in the mortality rates between the HES(+), LR(-) group and the HES(-), $\mathrm{LR}(-)$ group $(\mathrm{P}=0.308)$. There was no significant difference in the mortality rates between the $\operatorname{HES}(-), \operatorname{LR}(+)$ group and 
Table 1 Baseline patient characteristics for the observation and control groups

\begin{tabular}{lccc}
\hline Patient characteristics & $\begin{array}{c}\text { Observation } \\
\text { group }(\mathrm{n}=40)\end{array}$ & $\begin{array}{c}\text { Control group } \\
(\mathrm{n}=89)\end{array}$ & P value \\
\hline Age (year) & $59.12 \pm 17.91$ & $59.43 \pm 14.74$ & 0.921 \\
Height (cm) & $165.25 \pm 7.27$ & $166.3 \pm 7.23$ & 0.538 \\
Weight (kg) & $66.66 \pm 13.77$ & $65.19 \pm 10.42$ & 0.551 \\
Male sex, n (\%) & $28(70.0)$ & $54(60.9)$ & 0.548 \\
Underlying disease & & & \\
Hypertension, $\mathrm{n}(\%)$ & $12(30.0)$ & $17(19.1)$ & \\
Diabetes, $\mathrm{n}(\%)$ & $6(15.0)$ & $7(7.8)$ & \\
Other, $\mathrm{n}(\%)$ & $17(42.5)$ & $21(23.5)$ & \\
Diagnosis on ICU admission & & & \\
Vasopressor drug, $\mathrm{n}(\%)$ & $21(52.5)$ & $40(44.9)$ & 0.451 \\
Erythrocyte, $\mathrm{n}(\%)$ & $19(47.5)$ & $60(67.4)$ & 0.050 \\
Vital sign in emergency & & & 0.682 \\
Respiration (/min) & $21.95 \pm 5.51$ & $22.48 \pm 7.25$ & 0.686 \\
Heart rate (bpm) & $102.27 \pm 25.36$ & $99.07 \pm 21.67$ & 0.466 \\
MAP (mmHg) & $54.7 \pm 14.46$ & $51.39 \pm 13.18$ & 0.256 \\
\hline
\end{tabular}

Table 2 The in-hospital mortality for each group

\begin{tabular}{lcc}
\hline Prognosis & Deaths & Surviving patients \\
\hline Observation group & 2 & 38 \\
Control group & 11 & 77 \\
HES(+), LR(+) group & 10 & 75 \\
HES(+), LR(-) group & 1 & 3 \\
HES(-), LR(+) group & 2 & 9 \\
HES(-), LR(-) group & 0 & 9 \\
\hline
\end{tabular}

the HES(+), LR(+) group $(\mathrm{P}=0.511)$. In conclusion, using a small dose of HES 130/0.4 sodium chloride did not increase in-hospital mortality (see Table 2 and Figure 2).

\section{Changes in renal function}

Before fluid resuscitation, the CR levels of patients in the control group were lower than those of patients in the observation group $(102.83 \pm 73.19$ vs. $132.45 \pm 87.58$; $\mathrm{P}=0.0479)$. The CR levels of patients in the HES(-), LR(-) group were higher than those of patients in the HES(+),

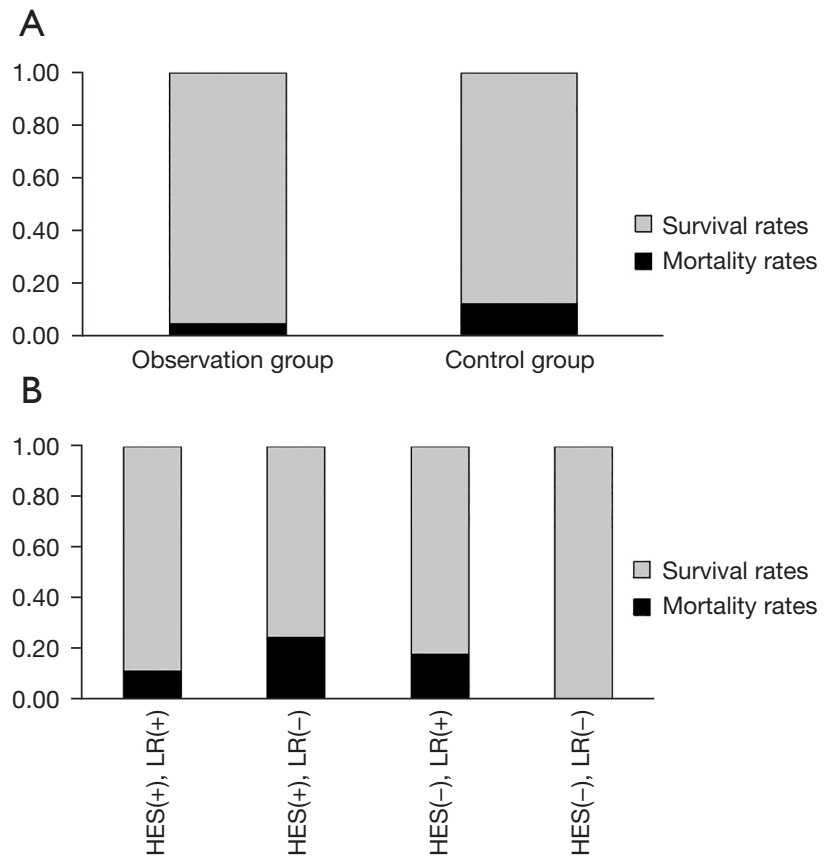

Figure 2 The in-hospital mortality rate for each group. A shows the mortality rates for the observation and control groups. B shows the mortality rates for the HES(+), LR(+) group, $\operatorname{HES}(+), \operatorname{LR}(-)$ group, $\operatorname{HES}(-), \mathrm{LR}(+)$ group, and $\mathrm{HES}(-), \mathrm{LR}(-)$ group.

LR(+) group and the HES(-), LR(+) group $(218.22 \pm 76.15$ vs. $99.35 \pm 65.36,218.22 \pm 76.15$ vs. $107.55 \pm 73.87 ; \mathrm{P}<0.05)$. After fluid resuscitation in the emergency room, there was no significant difference in the CR levels between patients in the observation and control groups $(102.83 \pm 73.19 v \mathrm{~s}$. $132.45 \pm 87.58 ; \mathrm{P}=0.082)$. In the observation group, there was no significant difference in the CR levels of patients after fluid resuscitation $(132.45 \pm 87.58$ vs. $127.28 \pm 119.78$; $\mathrm{P}=0.284)$. After fluid resuscitation, The CR levels of patients in the control group were lower than before resuscitation $(102.83 \pm 73.19$ vs. $97.56 \pm 71.14 ; \mathrm{P}=0.034)$. The $\mathrm{CR}$ levels of patients in the HES(+), LR(+) group were shorter after resuscitation than before resuscitation $(99.35 \pm 65.36$ vs. 93.51 $\pm 58.69 ; \mathrm{P}=0.028)$. There was no significant difference in the CR levels of patients in the HES(+), LR(-) group after fluid resuscitation $(176.75 \pm 150.58$ vs. $183.75 \pm 177.89$; $\mathrm{P}=0.999)$. In conclusion, when HES130/0.4 sodium chloride solution alone was used, there was no significant change in CR levels; however, when a combination of HES130/0.4 sodium chloride and LR was used for fluid resuscitation, CR levels decreased (see Tables 3,4 and Figures 3,4). 
Table 3 Comparison of renal function between the 2 groups

\begin{tabular}{lccc}
\hline Group & $\begin{array}{c}\text { Observation } \\
\text { group }\end{array}$ & $\begin{array}{c}\text { Control } \\
\text { group }\end{array}$ & P value \\
\hline $\mathrm{CR}(\mu \mathrm{mol} / \mathrm{L})$ & & & \\
Before resuscitation & $132.45 \pm 87.58$ & $102.83 \pm 73.19$ & $0.0479^{*}$ \\
After resuscitation & $127.28 \pm 119.78$ & $97.56 \pm 71.14$ & 0.0817 \\
P value & 0.2840 & $0.0341^{*}$ & \\
\hline
\end{tabular}

*, represents $\mathrm{P}<0.05$.

\section{Changes in CR levels in patients with high CR levels before resuscitation}

Of the 129 patients, the CR level was higher than normal in 19 patients $(47.5 \%)$ in the observation group and 23 patients $(25.9 \%)$ in the control group before resuscitation. After fluid therapy in the emergency department, patients' CR levels decreased in both the observation and control groups $(191.96 \pm 94.26$ vs. $173.82 \pm 100.46 ; \mathrm{P}=0.000 ; 202.37 \pm 83.09$ vs. 195.16 $\pm 149.61 ; \mathrm{P}=0.000)$. Notably, the decrease in CR levels in the observation group was significantly lower than that in the control group (see Table 5 and Figure 5).

\section{Discussion}

Shock is a life-threatening circulatory failure caused by an imbalance between the supply and demand for cellular oxygen, which is characterized by microcirculation disorder and the hypoperfusion of vital organs. There are 4 major categories of shock: hypovolemic shock, distributive shock, cardiogenic shock, and obstructive shock. Different kinds of shock have their own characteristics in terms of occurrence and development; however, they all damage capillary endothelial cells and can lead to insufficient perfusion, and functional and metabolic disorders in some important vital organs due to ischemia. The infusion of adequate fluid can help patients to maintain effective blood volume; however, fluid overload can result in cardiac failure and subsequent pulmonary edema and hypoxia (24). Patients with early septic shock are frequently hypovolemic due to decreased of food intake and increased loss of blood volume. AKI is a common complication in critically ill patients, especially shock patients. In the early stage of shock, the decrease of effective circulating blood volume and the increase of catecholamine secretion can lead to the contraction of renal afferent arterioles, which decreases the glomerular filtration rate. The renal tubules in the cortex become necrotized in the late stage of shock due to ischemia, which can also increase the accidence of AKI. CR is associated with renal function. When the filtering functions are injured, the excretion of CR from urine may decrease, which in turn causes the CR concentration in the blood to increase significantly. Thus, doctors often assess renal function by CR. In the present study, we evaluated renal function by comparing changes in patients' CR levels.

In this study, we explored the effect of a small dose of HES 130/0.4 sodium chloride on kidney function and found that there was no significant difference in patients' CR levels when HES 130/0.4 sodium chloride alone was used for fluid resuscitation, but that patients' CR levels decreased when both HES 130/0.4 sodium chloride and LR were used. In relation to the effect of a small dose of HES 130/0.4 sodium chloride, patients with high CR levels before resuscitation had lower CR levels after resuscitation in both the observation and control groups, which further confirmed that a small dose of HES 130/0.4 sodium chloride does not aggravate renal function.

We also found that there was no significant difference in the in-hospital mortality rates between the observation and control groups. Further, in comparing the mortality rates of the 4 groups, we found that there was no significant difference in the mortality rates between the HES(+), LR(-) group and the HES(-), LR(-) group, or between the HES(-), $\mathrm{LR}(+)$ group and the HES(+), LR(+) group. Muller et al. conducted a multicenter study of patients with severe sepsis and septic shock in 15 Southern French intensive care units (ICU), and reported that HES was widely used to treat patients with severe sepsis and septic shock in the initial 24-hour period, but did not have a deleterious effect on renal function (25). Similarly, other studies have reported findings that are consistent with our results $(26,27)$. However, other randomized control trials (e.g., the 6S, CRYSTMAS, and CHEST studies) found an increased risk of AKI when using HES130/0.4 in septic patients $(21,28,29)$. In the CRYSTMAS study (28), the HES patients were treated with $1,379 \mathrm{~mL}$ of HES on average, an amount more than twice that administered in the present study. Additionally, the results of an animal research study also indicated that HES 130/0.4 impairs kidney function in vivo without inflammation (30). However, it should be noted that the animals were infused with $50 \mathrm{~mL} / \mathrm{kg}$ of HES $130 / 0.4$ over 6 hours in that study.

Schortgen et al. (31) reported that renal dysfunction was predominant in ICU patients with septic shock who received HES, but this did not result in an increase in mortality or the need for CRRT (continuous renal replacement 
Table 4 Comparison of renal function between the 4 groups

\begin{tabular}{lllll}
\hline Group & HES $(+), \operatorname{LR}(+)$ & HES $(+), \operatorname{LR}(-)$ & HES $(-), \operatorname{LR}(+)$ & HES $(-), \operatorname{LR}(-)$ \\
\hline CR $(\mu \mathrm{mol} / \mathrm{L})$ & & & & \\
Before resuscitation & $99.35 \pm 65.36$ & $176.75 \pm 150.58$ & $107.55 \pm 73.87$ & $218.22 \pm 76.15^{\star, * \star \star}$ \\
After resuscitation & $93.51 \pm 58.69^{*}$ & $183.75 \pm 177.89$ & $115.26 \pm 117.95$ & $168.67 \pm 116.77$ \\
\hline
\end{tabular}

*, HES(+), LR(+) before resuscitation comparison; $\mathrm{P}<0.05$; ${ }^{\star \star \star}, \mathrm{HES}(-), \mathrm{LR}(+)$ before resuscitation comparison; $\mathrm{P}<0.05$.

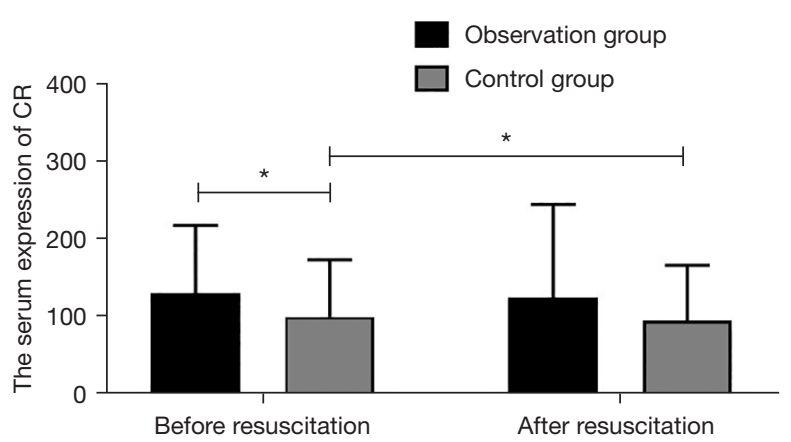

Figure 3 Comparison of creatinine (CR) before resuscitation and after resuscitation between the observation group and the control group. The results are shown as mean \pm standard deviation. Graphpad was used to calculate the $\mathrm{P}$ values. *, $\mathrm{P}<0.05$.

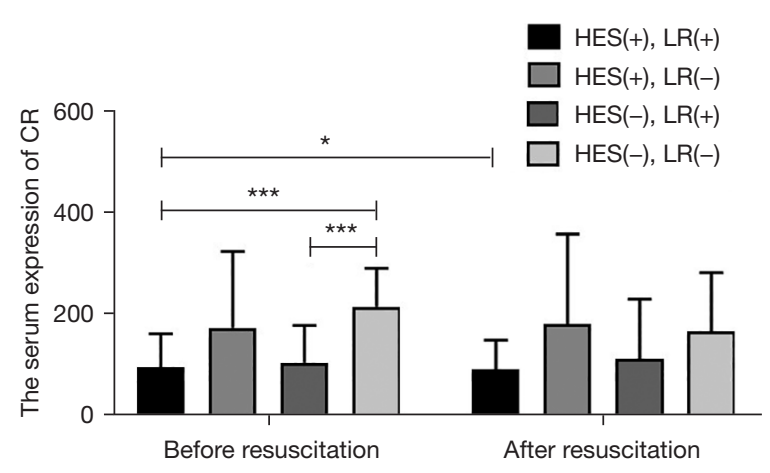

Figure 4 Comparison of creatinine (CR) before resuscitation and after resuscitation between the $\operatorname{HES}(+), \mathrm{LR}(+)$ group, the HES(+), LR(-) group, the HES(-), LR(+) group, and the HES(-), $\mathrm{LR}(-)$ group. The results are shown as mean \pm standard deviation. Graphpad was used to calculate the $\mathrm{P}$ values. *, represents $\mathrm{P}<0.05$; ***, represents $\mathrm{P}<0.001$.

therapy). Additionally, a multivariate analysis did not find that HES was associated with an increased risk of renal dysfunction. Boussekey et al. (26) also failed to find that HES had a deleterious effect in patients with severe sepsis
Table 5 Changes of CR in patients with high CR before resuscitation

\begin{tabular}{lccc}
\hline Time & $\begin{array}{c}\text { Before } \\
\text { resuscitation }\end{array}$ & $\begin{array}{c}\text { After } \\
\text { resuscitation }\end{array}$ & P value \\
\hline Observation group & $191.96 \pm .94 .26$ & $173.82 \pm 100.46$ & 0.000 \\
Control group & $202.37 \pm 83.09$ & $195.16 \pm 149.61$ & 0.000 \\
\hline
\end{tabular}

Observation group Control group

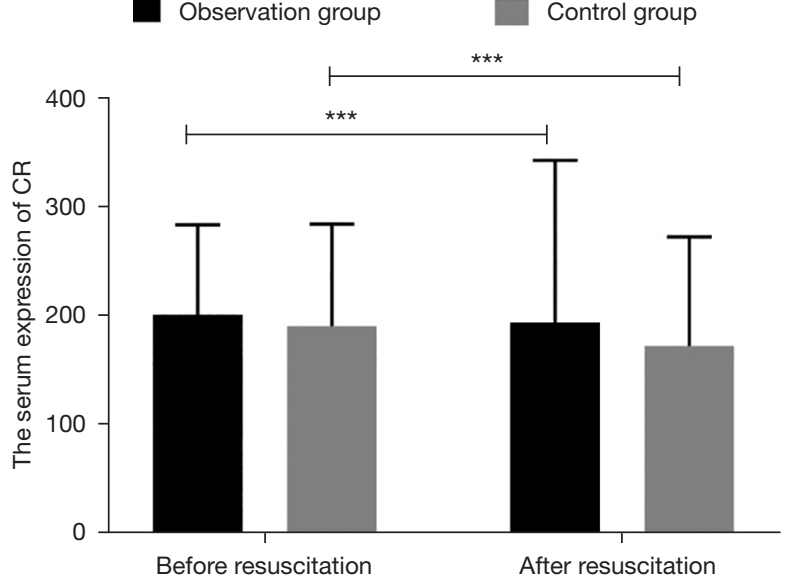

Figure 5 Comparison between the observation and control groups of creatinine (CR) levels before resuscitation and after resuscitation in patients with higher CR levels. The results are shown as mean \pm standard deviation. Graphpad was used to calculate the $\mathrm{P}$ values. ***, represents $\mathrm{P}<0.001$.

and/or septic shock. In the present study, we focused on the use of different fluid resuscitation therapies in the first 24 hours in the initial management of shock patients in the emergency department. On average, these patients received $806.89 \mathrm{~mL} / \mathrm{d}$ of HES 130/0.4 sodium chloride solution, an amount lower than that administered in other studies. A study on the effect of 6\% HES 130/0.4 administration on hematology and clinical chemistry parameters revealed that other than an effect on amylase activity, HES 130/0.4 had no clinically relevant effect on the other parameters tested 
in the study (32). Thus, HES 130/0.4 appears to have no effect if it has a low molecular weight and low dose.

HES is a synthetic colloid derived from partially hydrolyzed (33) and is metabolized by the kidneys. HES $130 / 0.4$ is one of the most widely used hydroxyethyl products in clinical settings. 'Compared to previous generation preparations with larger molecular weights (e.g., HES200/0.6), HES 130/0.4 significantly reduces the adverse effects of renal and coagulation function while retaining the advantages (34). There is no relevant plasma accumulation after repetitive infusions of the medium-molecular weight HES (130/0.4) solution (35). In addition, several studies have reported that HES can be safely used in patients with renal dysfunction (36,37). In this analysis, the CR levels of patients decreased after HES 130/0.42 sodium chloride and LR were used. These results are inconsistent with those of previous studies (38). There could be a number of reasons for this inconsistency. First, HES increases the risk of renal injury in shock patients during fluid resuscitation, which is positively correlated with dose of HES. In addition, the elimination of HES is related to the molecular weight, especially the substitution level. The high molecular weight of HES is degraded by amylase, and when its molecular weight is $<7,000 \mathrm{D}$, it can be quickly removed through the glomerulus. HES 130/0.4 is a synthetic colloid with a medium-molecular weight and a low substitution level. The amount of HES in our study was lower than that used in previous studies. This may be why we found that patients' CR levels were lower after resuscitation. Second, CR levels may have decreased because of blood dilution after the infusion of large amounts of fluids.

At present, there is no consensus as to the renal effect of colloid solutions, such as HES130/0.4 sodium chloride solution, in shock patients. The inconsistencies in the results of different studies may be related to the complicated conditions of patients. In the future, we will increase the sample size and strictly control for confounding factors to further explore the effect of HES130/0.4 sodium chloride solution in the treatments of shock patients, and thus provide more evidence for clinicians.

\section{Limitations}

This study had several limitations. There was no significant difference in renal function when HES 130/0.4 sodium chloride alone was used for fluid resuscitation; however, the small number of patients in the HES(+), LR(-) group may have affected the accuracy of our results. Second, as this is a retrospective single cohort study, bias may exist. Third, the time of fluid resuscitation in each patient in the emergency room differed and the administration of other usual types of therapy may have affected the clinical effects of the fluid resuscitation.

\section{Conclusions}

In conclusion, HES and LR are commonly used drugs in fluid therapy. However, when the 2 drugs are used in combination, they may not increase kidney injury. Additionally, the use of a small dose of HES in resuscitation does not appear to cause any significant side effects; however, our findings need to be confirmed with larger clinical studies.

\section{Acknowledgments}

Funding: This research received funding from the National Natural Science Foundation of China Youth Fund (81801893), the Nantong Clinical Medicine Research Center (HS2019005), Natural Science Research Project of Nantong Science and Technology Bureau (MS12021021, MS12020006, MS12020017, MS12021035), Special Fund for Emergency Medical Research of Ruiyi of Peking Union Medical College Hospital (R2019023), Jiangsu Planned Projects for Postdoctoral Research Fund (2021K031A), Deputy General Manager Project of Science and Technology of Jiangsu Province (FZ20210652), Jiangsu geriatric clinical technology application research project (LR2021047).

\section{Footnote}

Reporting Checklist: The authors have completed the STROBE reporting checklist. Available at https://dx.doi. org/10.21037/tau-21-972

Data Sharing Statement: Available at https://dx.doi. org/10.21037/tau-21-972

Conflicts of Interest: All authors have completed the ICMJE uniform disclosure form (available at https://dx.doi. org/10.21037/tau-21-972). The authors have no conflicts of interest to declare.

Etbical Statement: The authors are accountable for all aspects of this work, including ensuring that any questions 
related to the accuracy or integrity of any part of the work have been appropriately investigated and resolved. This study was approved by the Ethics Committee of the Affiliated Hospital of Nantong University (2017-L021) and consent was obtained from the patients and their families. All procedures performed in this study involving human participants were in accordance with the Declaration of Helsinki (as revised in 2013).

Open Access Statement: This is an Open Access article distributed in accordance with the Creative Commons Attribution-NonCommercial-NoDerivs 4.0 International License (CC BY-NC-ND 4.0), which permits the noncommercial replication and distribution of the article with the strict proviso that no changes or edits are made and the original work is properly cited (including links to both the formal publication through the relevant DOI and the license). See: https://creativecommons.org/licenses/by-nc-nd/4.0/.

\section{References}

1. Levy JH. Treating shock--old drugs, new ideas. N Engl J Med 2010;362:841-3.

2. Ospina-Tascón GA, Calderón-Tapia LE. Inodilators in septic shock: should these be used? Ann Transl Med 2020;8:796.

3. Martin GS. Sepsis, severe sepsis and septic shock: changes in incidence, pathogens and outcomes. Expert Rev Anti Infect Ther 2012;10:701-6.

4. Heckbert SR, Vedder NB, Hoffman W, et al. Outcome after hemorrhagic shock in trauma patients. J Trauma 1998;45:545-9.

5. Grånäs C, Lundholt BK, Heydorn A, et al. High content screening for $\mathrm{G}$ protein-coupled receptors using cellbased protein translocation assays. Comb Chem High Throughput Screen 2005;8:301-9.

6. Zhang Z, Zhu C, Mo L, et al. Effectiveness of sodium bicarbonate infusion on mortality in septic patients with metabolic acidosis. Intensive Care Med 2018;44:1888-95.

7. Corrêa TD, Rocha LL, Pessoa CM, et al. Fluid therapy for septic shock resuscitation: which fluid should be used? Einstein (Sao Paulo) 2015;13:462-8.

8. Silva J, Gonçalves L, Sousa PP. Fluid therapy and shock: an integrative literature review. Br J Nurs 2018;27:449-54.

9. Schortgen F, Deye N, Brochard L, et al. Preferred plasma volume expanders for critically ill patients: results of an international survey. Intensive Care Med 2004;30:2222-9.

10. Miletin MS, Stewart TE, Norton PG. Influences on physicians' choices of intravenous colloids. Intensive Care Med 2002;28:917-24.

11. Finfer S, Liu B, Taylor C, et al. Resuscitation fluid use in critically ill adults: an international cross-sectional study in 391 intensive care units. Crit Care 2010;14:R185.

12. Myburgh JA. Fluid resuscitation in acute medicine: what is the current situation? J Intern Med 2015;277:58-68.

13. Levy MM, Evans LE, Rhodes A. The Surviving Sepsis Campaign Bundle: 2018 update. Intensive Care Med 2018;44:925-8.

14. Wu XQ, Li ZB, Chen WX, et al. The influence of different resuscitation solution on lactic acid accumulation after hemorrhagic shock: a network meta-analysis. Eur Rev Med Pharmacol Sci 2019;23:6707-17.

15. American Thoracic Society. Evidence-based colloid use in the critically ill: American Thoracic Society Consensus Statement. Am J Respir Crit Care Med 2004;170:1247-59.

16. Brunkhorst FM, Engel C, Bloos F, et al. Intensive insulin therapy and pentastarch resuscitation in severe sepsis. $\mathrm{N}$ Engl J Med 2008;358:125-39.

17. Hydroxyethyl Starch or Saline for Fluid Resuscitation in Intensive Care. N Engl J Med 2016;374:1298.

18. Niemi TT, Miyashita R, Yamakage M. Colloid solutions: a clinical update. J Anesth 2010;24:913-25.

19. Ragaller MJ, Theilen H, Koch T. Volume replacement in critically ill patients with acute renal failure. J Am Soc Nephrol 2001;12 Suppl 17:S33-9.

20. Marx G, Pedder S, Smith L, et al. Resuscitation from septic shock with capillary leakage: hydroxyethyl starch $(130 \mathrm{kd})$, but not Ringer's solution maintains plasma volume and systemic oxygenation. Shock 2004;21:336-41.

21. Perner A, Haase N, Guttormsen AB, et al. Hydroxyethyl starch 130/0.42 versus Ringer's acetate in severe sepsis. N Engl J Med 2012;367:124-34.

22. Pelage JP, Fohlen A, Mitry E, et al. Erratum to: Chemoembolization of Neuroendocrine Liver Metastases Using Streptozocin and Tris-acryl Microspheres: Embozar (EMBOsphere + ZAnosaR) Study. Cardiovasc Intervent Radiol 2017;40:480.

23. Yang ZY, Wang CY, Jiang HC, et al. Effects of early goaldirected fluid therapy on intra-abdominal hypertension and multiple organ dysfunction in patients with severe acute pancreatitis. Zhonghua Wai Ke Za Zhi 2009;47:1450-4.

24. Zhang Z, Ni H, Qian Z. Effectiveness of treatment based on PiCCO parameters in critically ill patients with septic shock and/or acute respiratory distress syndrome: a randomized controlled trial. Intensive Care Med 2015;41:444-51. 
25. Muller L, Jaber S, Molinari N, et al. Fluid management and risk factors for renal dysfunction in patients with severe sepsis and/or septic shock. Crit Care 2012;16:R34.

26. Boussekey N, Darmon R, Langlois J, et al. Resuscitation with low volume hydroxyethylstarch $130 \mathrm{kDa} / 0.4$ is not associated with acute kidney injury. Crit Care 2010;14:R40.

27. Sakr Y, Payen D, Reinhart K, et al. Effects of hydroxyethyl starch administration on renal function in critically ill patients. Br J Anaesth 2007;98:216-24.

28. Guidet B, Martinet O, Boulain T, et al. Assessment of hemodynamic efficacy and safety of $6 \%$ hydroxyethylstarch $130 / 0.4$ vs. $0.9 \% \mathrm{NaCl}$ fluid replacement in patients with severe sepsis: the CRYSTMAS study. Crit Care 2012;16:R94.

29. Myburgh JA, Finfer S, Bellomo R, et al. Hydroxyethyl starch or saline for fluid resuscitation in intensive care. $\mathrm{N}$ Engl J Med 2012;367:1901-11.

30. Schick MA, Baar W, Bruno RR, et al. Balanced Hydroxyethylstarch (HES 130/0.4) Impairs Kidney Function In-Vivo without Inflammation. PLoS One 2015;10:e0137247.

31. Schortgen F, Lacherade JC, Bruneel F, et al. Effects of hydroxyethylstarch and gelatin on renal function in severe sepsis: a multicentre randomised study. Lancet 2001;357:911-6.

32. Mueller T, Schimetta W, Dieplinger B, et al. Influence of hydroxyethyl starch (6\% HES 130/0.4) administration on hematology and clinical chemistry parameters. Clin Chem Lab Med 2008;46:558-62.

33. Jungheinrich C, Neff TA. Pharmacokinetics of hydroxyethyl starch. Clin Pharmacokinet 2005;44:681-99.

34. Blasco V, Leone M, Antonini F, et al. Comparison of the novel hydroxyethylstarch 130/0.4 and hydroxyethylstarch 200/0.6 in brain-dead donor resuscitation on renal function after transplantation. Br J Anaesth 2008;100:504-8.

35. Waitzinger J, Bepperling F, Pabst G, et al. Hydroxyethyl starch (HES) 130/0.4, a new HES specification: pharmacokinetics and safety after multiple infusions of $10 \%$ solution in healthy volunteers. Drugs R D 2003;4:149-57.

36. Winkelmayer WC, Glynn RJ, Levin R, et al. Hydroxyethyl starch and change in renal function in patients undergoing coronary artery bypass graft surgery. Kidney Int 2003;64:1046-9.

37. Dehne MG, Mühling J, Sablotzki A, et al. Hydroxyethyl starch (HES) does not directly affect renal function in patients with no prior renal impairment. J Clin Anesth 2001;13:103-11.

38. Di Prospero L. Message de la Rédactrice en Chef. J Med Imaging Radiat Sci 2014;45:65-7.

(English Language Editor: L. Huleatt)
Cite this article as: Jiang H, Ren Y, Qi G, Wang Y, Xu C, Mao G, Liang G, Yan D, Yan Y, Dong Y, Huang Z, Qi L. The effect of HES130/0.4 sodium chloride solution on kidney function following early fluid resuscitation in shock patients. Transl Androl Urol 2021;10(11):4288-4297. doi: 10.21037/ tau-21-972 